\title{
Transradial Approach for Coronary Interventions
}

\author{
José Carlos Brito, Antônio Azevedo Júnior, Adriano Oliveira, Roberto Von Sohsten, Ademar Santos Filho, \\ Heitor Carvalho
}

Salvador, BA - Brazil

Objective - To assess the feasibility and safety of coronary interventions performed through the radial artery.

Methods - We studied 103 patients with ages from 38 to 86 years (57士8.7), 90 (87\%) males, and: radial pulse with a good amplitude, presence of ulnar pulse, a good collateral flow through the palmar arch assessed with the Allen's test.

Results - The vascular approach was obtained in 97 (94\%) patients, 88 (91\%) treated electively and 9 (9\%) during acute myocardial infarction, for primary angioplasty; 56 (64\%) unstable angina; 22 (25\%) stable angina; 10 (11\%) were asymptomatic, 6 referred for recanalization of chronic occlusion and 4 silent ischemia in the first week after acute myocardial infarction. We approached 107 arteries: anterior descending artery, 49 (46\%); right coronary artery, 27 (25\%); circumflex artery, 25 (23\%); diagonal artery, 6 (6\%); and 2 saphenous vein bypass grafts. We treated 129 lesions: 80 (62\%) B2 type; 23 (18\%) B1 type; 17 (13\%) C type; and 9 (7\%). Atype. Therewere 70 stents, and 59 balloon angioplasties performed. Thirty-two (33\%) patients used GP IIb/IIIa inhibitors. The mean duration of the elective procedure was $42.3 \pm 12.8 \mathrm{~min}$. Success, correctstent deployment andresidual lesion $<20 \%$, was reached in $100 \%$ of the lesions treated with stent implantation; arterial dilation with residual lesion $<50 \%$ was obtained in $96 \%$ of the lesions treated with transluminal coronary angioplasty (TCA). Complications, were: 1 (1.0\%) non-Q-wave acute myocardial infarction; 2 (2\%) hematomas in the forearm; and 2 losses of radial pulse.

Conclusion-Radial artery aproach is practical and safe for percutaneous coronary interventions there was a low incidence of complications.

Keywords: radial artery, percutaneous interventions.

Hospital Português and Hospital Santa Izabel - Salvador

Mailing address: José Carlos Brito - Rua Wanderley de Pinho, 305/302 - 41841-300

- Salvador, BA, Brazil

English version by Stela Maris C. Gandour
Percutaneous coronary interventions are usually performed through the femoral artery. Despite advances in the materials used, vascular complications and bleeding in the site of puncture persist, being more frequent in obese patients, those with aorta-iliac disease, those under anticoagulant treatment, those using GP IIb/IIIa inhibitors or in the acute phase of myocardial infarction treated with fibrinolytic agents, all of which prolong hospital stay and increase costs ${ }^{1}$.

The radial approach has been widely accepted based on the initial studies by Campeau ${ }^{2}$ and Kiemeneij ${ }^{3-5}$ on coronary angiography and angioplasty, respectively.

The major advantages of the radial approach are the reduction in the incidence of complications related to the site of puncture, early ambulation, short hospital stay, and reduction in costs ${ }^{6}$.

The technique requires a selection of candidates based on the good amplitude of the pulse, and involves an assessment of collateral circulation between the radial and ulnar arteries through the palmar $\operatorname{arch}^{2,7}$.

This prospective observational study aimed to analyze the feasibility and safety of performing coronary interventions through the radial artery.

\section{Methods}

Patients with indication for coronary angioplasty were assessed in the hemodynamic unit and selected according to the following criteria: presence of radial pulse of good amplitude, presence of ulnar pulse, and a good collateral flow through the palmar arch assessed by the Allen's test. Patients with indication for rotational atherectomy, intracoronary ultrasound, and intraaortic balloon were excluded from the study. After selection, the patients were referred to the hemodynamic unit and prepared for radial and femoral approaches. Radial punctures were performed using the transradial Cordis-Johnson-Johnson kit, which consisted of a 19-gauge needle, a 0.022 " guide-wire, a $6 \mathrm{~F}$ sheath, and progressive dilators. Then, 5,000 units of heparin diluted in $0.9 \mathrm{~mL}$ of saline solution were injected through the introducer, in addition to a solution of $0.1 \mathrm{~mL}$ of isosorbide mononi- 
trate and $1 \mathrm{~mL}$ of $2 \%$ lidocaine aiming at reducing spasm and local pain. The remaining heparin required in the procedure was administered by peripheral venous via. With the protection of guide wires of 0.032 ", guiding catheters were introduced up to the ascending aorta. The catheters were chosen according to the anatomy to provide good support and also according to the technician's criterion. Routinely, following predilation with the balloon, the stents were deployed with pressures ranging from 12 to 18 atmospheres.

At the end of the procedures, the introducers were immediately withdrawn, and compression of the site of puncture was started for 6 to 8 hours until total hemostasis was obtained through the use of folded gauze and an adequate elastic belt. All patients were referred to the coronary unit for observation, where they remained for a period not less than 12 hours. The following parameters were assessed: 1) success in the vascular approach; 2) success with the lesion treated, defined as residual lesion $<50 \%$ for TCA, and as correct implant with residual lesion $<20 \%$ for stent; 3 ) duration of the procedure; 4) duration of hospital stay in elective patients; 5) complications in the first 24 hours after the procedure.

\section{Results}

From July'98 to November'99, 103 patients with coronary artery disease were selected for percutaneous coronary revascularization through the radial artery, comprising $43 \%$ of the 236 patients treated in the same period of time.

The right radial artery was approached in 97 (94\%) of the 103 patients selected. The 6 patients, in whom the radial approach was not obtained, were successfully treated through the femoral via. Age ranged from 38 to 86 years (mean of $57 \pm 8.7$ ), and $90(87 \%$ ) patients were males. Interventions were elective in $88(91 \%)$ patients, of whom $56(64 \%)$ had unstable angina, $22(25 \%)$ had stable angina, and 10 (11\%) were asymptomatic. Of these asymptomatic patients, 6 were referred for reopening of chronic arterial occlusion and 4 had positive functional tests for ischemia in the first week after acute myocardial infarction. Nine patients (9\%) with acute myocardial infarction underwent the procedure on an emergency basis, aiming at reperfusion.

We approached 107 arteries, the anterior descending artery being the most frequently accessed (49-46\%), followed by the right coronary artery $(27-25 \%)$, circumflex artery $(25-$ $23 \%$ ), and diagonal artery $(6-6 \%)$, and 2 saphenous vein bypass grafts, one to the right coronary artery and the other to the circumflex artery summing up 109 vessels (fig. 1).

We treated 129 lesions with the following angiographic characteristics according to the classification of the American College of Cardiology/American Heart Association Task Force: 80 (62\%) lesions of the B2 type; 23 (18\%) lesions of the B1 type; 17 (13\%) lesions of the $\mathrm{C}$ type; and 9 (7\%) of the A type (fig. 2).

The most used guiding catheters were the following: the multipurpose, used in $85 \%$ of the cases for the treatment of the right coronary artery; the XB extra-support back-up, used in $82 \%$ of the cases in which the anterior descending ar-

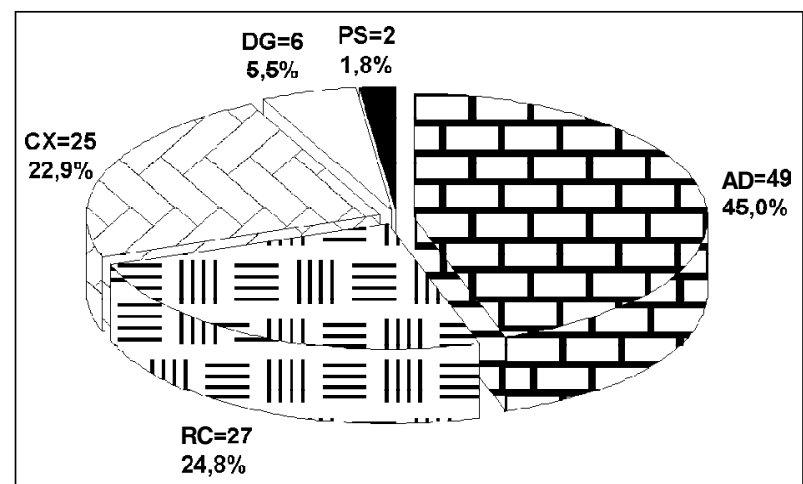

Fig. 1 - Vessels and grafts treated. AD- anterior descending artery; RC- right coronary artery; CX- circumflex artery; DG- diagonal branch of the anterior descending artery; SVBG- saphenous vein bypass graft.

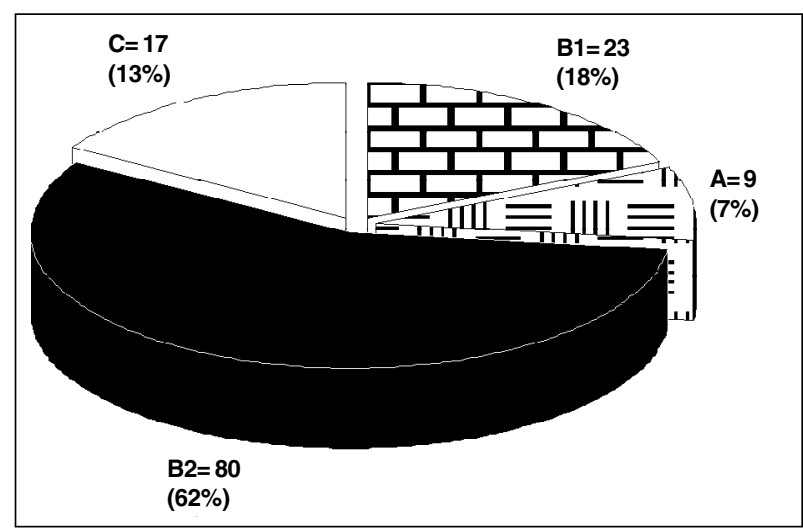

Fig. 2 - Characteristics of the lesions treated according to the classification of the American College of Cardiology/American Heart Association Task Force: A, B1, B2, and C.

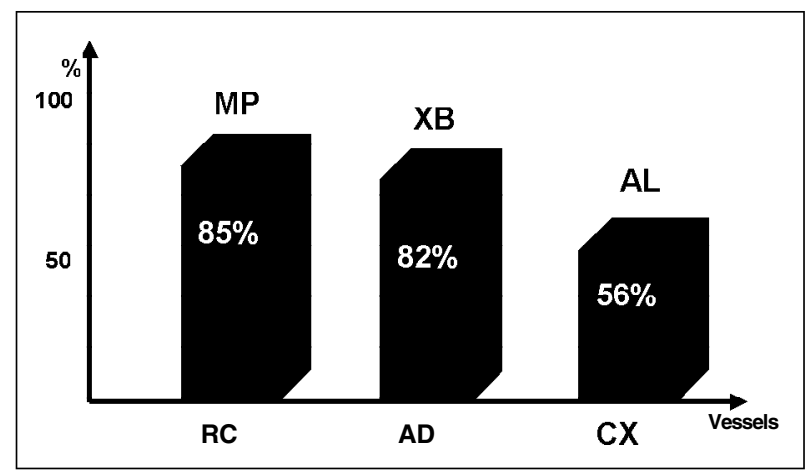

Fig. 3 - Most used guiding catheters according to the vessel treated. RC- right coronary artery; $\mathrm{AD}$ - anterior descending artery; $\mathrm{CX}$ - circumflex artery; MP- multipurpose catheter; AL- left Amplatz catheter. XB - Extra support back-up.

tery was approached; and the left Amplatz, used in 56\% of the angioplasties of the circumflex artery (fig. 3).

Seventy stents were implanted and 59 balloon angioplasties performed. Thirty-two (33\%) patients used GPIIb/ IIIa inhibitors. The most used stent was the NIR Primo (Boston Scientific Scimed, Jerusalem, Israel), which was implanted in 26 patients, followed by the AVE (Medtronic Inc., Minneapolis, USA) implanted in 12 patients, the BE-Stent (Medtronic Inc., Minneapolis, USA) in 11, Multilink (Gui- 
dant Corporation, Indianapolis, USA) in 7, Pura-Vario (Devon Medical, Hamburg, Germany) in 7, Jostent (Jomed, GmbH Rangendinger, Germany) in 4, and the Euca Stent (Eucatech, GmbH, Kissingen, Germany).

The radial approach was achieved in 97 (94\%) out of 103 patients selected for this technique. In all patients in whom the vascular approach was obtained, the selective intubation of coronary ostia was possible with appropriate support. The mean duration of the procedures in the elective patients was $42.3 \pm 12.8 \mathrm{~min}$. Success was obtained in 70 $(100 \%)$ out of the 70 lesions treated with stent implantation, and in $57(96 \%)$ out of the 59 lesions treated with TCA.

The following complications were observed: non-Qwave infarction in $1(1 \%)$ patient due to occlusion of the circumflex artery 2 hours after TCA, which was successfully treated with stent implantation; hematoma in the forearm in 2 (2\%) patients, one of whom required surgical drainage; and asymptomatic loss of the radial pulse in $2(2 \%)$ patients. Emergency surgery, Q-wave infarction, need for transfusion, and death did not occur. In the elective patients, the mean duration of hospital stay after intervention was $27 \pm 6.4 \mathrm{~h}$.

\section{Discussion}

Most of percutaneous coronary interventions are performed through the femoral artery. Despite the availability of lowprofile material and early withdrawal of introducers, complications related to the site of puncture persist, particularly in patients using high doses of anticoagulant drugs, fibrinolytic agents, and GP IIb/IIIa inhibitors ${ }^{1}$. In obese individuals and in those with severe aorta-iliac disorders, the femoral approach may be difficult or even impossible. In addition, immobilization of the lower limbs and prolonged rest are recommended after the intervention, increasing hospital stay ${ }^{8}$.

Despite the possibility of the percutaneous approach, the brachial artery, which was very often used through dissection in the beginning of coronary angioplasty, is more deeply located than the radial artery, accounts for a larger area of irrigation, and its occlusion may determine functional impairment of the limb 9,10 .

On the other hand, the radial artery is more superficially located, is easily approached, and also easily compressed. Loss of the radial pulse is minimized if a good collateral circulation is provided through the palmar arch, whose assessment through the Allen's test makes the technique extremely safe ${ }^{2,3,4,7,11}$.

Patients selected for the radial technique should meet the following criteria: radial pulse of good amplitude, presence of ulnar pulse, and a good collateral flow through the palmar arch shown in the Allen's test ${ }^{12}$. The Allen's test consists of 2 consecutive stages: simultaneous compression of the radial and ulnar arteries leading to palmar ischemia; with the radial artery compressed, the ulnar artery is set free. This maneuver in the presence of good collateral circulation through the palmar arch results in reversion of ischemia in less than $10 \mathrm{sec}$, which confirms the positivity of the test. In case of prolonged ischemia, the test is considered ischemic (negative), constituting a contraindication to the technique ${ }^{2,7,13-15}$. Allen's test may be replaced by the determination of oxygen saturation with the pulse oximeter, with which changes in the percentage of oxygen saturation values may be analyzed ${ }^{16}$.

Routinely, the right radial artery is used, which provides the same conditions of practical handling of the right brachial and femoral via. The left radial artery may be used in unsuccessful cases of right-side puncture, reduction in or absence of pulse due to previous brachial or radial catheterization, and approach of the left mammary artery ${ }^{17}$.

In patients requiring hemodynamic support, such as intraaortic balloon, or cardiopulmonary support, the femoral approach is unavoidable and, therefore, the femoral via is preferable. In the same way, patients undergoing a hemodialysis program or future candidates for this type of treatment should also be preferably approached through the femoral via.

The major advantage of using the radial via is reduction in the incidence of complications related to the site of puncture associated with early ambulation and no risk of bleeding, with reduction in hospital stay, and consequently in costs, making way for interventions in an outpatient care regimen ${ }^{18,19}$.

Kiemeneij et al. ${ }^{9}$, in a randomized study, compared the radial, femoral, and brachial approaches and observed a lower incidence in complications with the radial via.

Mann et al. ${ }^{6}$, in a prospective study, compared the costs of coronary angioplasties performed through the radial and femoral approaches and observed a significant reduction in complications related to the vascular approach, a smaller duration of hospital stay, and a reduction in the total cost of the procedure in the group treated through the radial approach.

Availability of the appropriate material is very important for the percutaneous approach of the radial artery and a learning curve has been reported with failure rates around $10 \%{ }^{2,5,14}$. In our study, we used the Cordis-Johnson-Johnson transradial kit, which comprised a 19-gauge needle, a 0.022 " guide wire, a $6 \mathrm{~F}$ (French) sheath, and progressive dilators, and we obtained access in $94 \%$ of the cases. The failures, most of which occurred in the initial phase, were successfully treated through the femoral via.

Another important detail is the choice of a guide wire that allows good support for approaching the target artery. The most common technical difficulties related to the catheterization of the coronary ostia using the radial artery may be overcome with initial training in coronary angiography. Impossibility of selective intubation of the coronary ostia may also occur due to tortuosity of the subclavian artery or important dilation of the ascending aorta ${ }^{2}$. Despite the recent manufacture of specific material for the radial artery approach, we used guiding catheters usually used for the femoral via, and we had no difficulty related to the support.

Few reports exist on the use of the radial via for performing primary angioplasty in acute myocardial infarction ${ }^{20,21}$. In our country, our study was the first report on the radial via for primary angioplasty. Our experience with coronary angiography using the radial artery made this initiative ea- 
sier, and we had no difficulty in approaching the artery involved in the infarction. The increasing use of the GP IIb/ IIIa inhibitors in primary angioplasty or associated with a thrombolytic agent makes the radial approach attractive due to greater risks of hemorrhagic complications in these patients. In our series of patients, no complications related to the vascular access occurred in the patients with acute myocardial infarction undergoing primary angioplasty, despite the use of GP IIb/IIIa inhibitors in all patients.

Despite the complexity of the lesions, $75 \%$ of which were B2 and C types according to the classification of the American College of Cardiology/American Heart Association Task Force ${ }^{22}$ modified by Ellis ${ }^{23}$, a high index of primary success was observed, $100 \%$ for the lesions treated with stent implantation and $96 \%$ for the lesions treated with balloon, as was a low incidence of complications. Recent studies have shown the efficacy and safety of using GP IIb/IIIa inhibitors during percutaneous coronary interventions ${ }^{1,2426}$. In addition, the incidence of acute complications following the intervention was reduced with stent implantation ${ }^{27}$. The use of latest generation of material, including low-profile and easy-handling stents, in addition to the use of GP IIb/IIIa inhibitors in $1 / 3$ of the patients may have positively influenced our results.

The major complications of this technique are the asymptomatic loss of the radial pulse (4\%) and the occurrence of hematomas $(0.7 \%)$, but a surgical intervention for the treatment of hematoma or arteriovenous fistulae has been rarely observed $(0.1 \%)^{15,28}$. The incidence of complications observed in this study overlaps the literature findings: asymptomatic loss of the radial pulse occurred in a low percentage of patients, even though patency of the radial artery was assessed only by the palpation method, unlike a few studies that used ultrasound ${ }^{14}$. The use of $6 \mathrm{~F}$ introducers and their withdrawal immediately after the procedure may have positively influenced the low rate of loss of the radial pulse observed in our series. The incidence of hematomas was also very low, considering that $33 \%$ of the patients used GP IIb/IIIa inhibitors.

The use of $6 \mathrm{~F}$ introducers reduces the incidence of arterial occlusion but, on the other hand, makes the use of other techniques, such as rotational atherectomy and intracoronary ultrasound, unfeasible. The use of $7 \mathrm{~F}$ and $8 \mathrm{~F}$ introducers has been reported depending on the diameter of the radial artery measured on ultrasound ${ }^{29,30}$.

Early hospital discharge with cost reduction is one of the major advantages of the radial via ${ }^{6}$. Other advantages are the reduction in nursing time and intensity with the access via, in addition to the patient's sensation of comfort with early ambulation ${ }^{31}$. In our experience, duration of hospital stay after intervention assessed only in the elective patients was small and overlapped the literature findings.

This study, however, has some limitations, such as the observational design and series report, which do not allow direct comparison with other techniques. Most of the interventions were performed by the same surgeon, which limited the conclusions. Hospital discharge of the patients treated electively did not depend only on the guidance of the team involved in the procedure, which may have increased the duration of hospital stay.

In conclusion, our study has shown that the radial artery may be safely used, constituting one more option of access for percutaneous coronary interventions, which is a technique that should be preferably considered in cases with relative or absolute contraindication to the femoral via (aorta-iliac disease, local infection) and when the risk of complications is high (obesity, oral anticoagulation, thrombolysis, and concomitant use of GP IIb/IIIa inhibitors). Early ambulation with no risk of bleeding reduces the duration of hospital stay and costs.

\section{References}

1. The EPIC investigators. Use of a monoclonal antibody directed against the platelet glycoprotein IIb/IIIa receptor in high-risk coronary angioplasty. N Engl J Med 1994; 330: 956-61.

2. Campeau L. Percutaneous radial artery approach for coronary angiography. Cathet Cardiovasc Diagn 1989; 16: 3-7.

3. Kiemeneij F, Laarman GJ. The radial artery: a safe entry site for coronary stenting. Circulation 1993; 88: I-587.

4. Kiemeneij F, Laarman GJ. Percutaneous transradial artery approach for coronary Palmaz-Schatz stent implantation. Am Heart J 1994; 128: 167-70.

5. Kiemeneij F, Laarman GJ, de Melker E. Transradial coronary angioplasty. Am Heart J 1995; 129: 1-7.

6. Tift Mann J, Cubeddu G, Schneider J, Arrowood M. Right radial access for PTCA: A prospective study demonstrates reduced complications and hospital charges. J Invas Cardiol 1996; 8: 40D-4D.

7. Jaspers L, Jackmaert C, Paelmans R, Coninx R, Smeets B, Benit E. Frequency of a positive Allen test in a population of patients undergoing cardiac catheterization (abstract). Eur Heart J 1995; T6(suppl): 1828.

8. Johnson LW, Esent P, Grambartolomei A, Grant WH, Loin M, Reger MJ. Peripheral vascular complications of coronary angioplasty by the femoral and brachial techniques. Cathet Cardiovasc Diagn 1994; 31: 165-72.

9. Kiemeneij F, Laarman GJ, Odekerken D, Slagboom T, Van der Wicken R. A randomized comparison of percutaneous transluminal coronary angioplasty by the ra- dial, brachial and femoral approaches: the Access study. J Am Coll Cardiol 1997; 29: 1269-75.

10. Fergusson DJG, Kamada RO. Percutaneous entry of the brachial artery for left heart catheterization using a sheath; further experience. Cathet Cardiovasc Diagn1986; 12: 209-11.

11. Grinfeld L, Berrocal D, Rojas Majas C, Magni J, Belardi J. What is the most effective vascular approach for a diagnosis cardiac catheterization? A randomized trial using the femoral, brachial or radial approach. J Am Coll Cardiol 1996; 27 : 901.

12. Allen EV. Thromboangitis obliterans: Methods of diagnosis of chronic occlusive arterial lesions distal to the wrist with illustrative cases. Am J Med Sci 1929; 178: 237- 44 .

13. Carvalho E, Jordan C, Fajadet J, et al. Percutaneous transradial coronary revascularization. J Am Coll Cardiol 1995; 25: I-301.

14. Lotan C, Hasin Y, Mosseri M, et al. Transradial approach for coronary angiography and angioplasty. Am J Cardiol 1995; 76: 164-7.

15. Barbeau G, Carrier G, Ferland S, Letourneau L, Gleeton O, Larivière M. Right transradial approach for coronary procedures: Preliminary results. J Invas Cardiol 1996; 8: 19D-21D

16. Fajadet J, Brunel P, Jordan C, Cassagneau B, Laurent JP, Marco J. Transradial approach for interventional coronary procedure: analysis of complications. J Am Coll Cardiol 1996; 27: 1032.

17. Spaulding C, Lefèvre T, Funck F. Left radial approach for coronary angiography: results of a prospective study. Cathet Cardiovasc Diagn 1996; 39: 365-70. 
18. Kiemeneij F, Laarman GJ, Slagboom T, Van der Wieken R. Outpatient coronary stent implantation. J Am Coll Cardiol 1997; 29: 323-7.

19. Slagbomm T, Kiemeneij F, Laarman G, Wieken R. Actual same day discharge after coronary angioplasty. Eur Heart J 1996; (suppl): 1973.

20. Saito S, Hosokawa G, Miyake S, Yamamoto S. Successful reperfusion with transradial angioplasty safety result in early ambulation and shorten hospital stay in a selected subgroup of acute myocardial infarction. The results of Kamakura PASTA Trial. J Am Coll Cardiol 1997; 29: 971.

21. Steg PG, Aubry P. Radial access for primary PTCA in patients with acute myocardial infarction and contraindication to or impossible femoral access. Cathet Cardiovasc Diagn 1996; 39: 424-6.

22. The EPILOG Investigators. Platelet glycoprotein IIb/IIIa receptor blockade and low-dose heparin during percutaneous coronary revascularization. N Engl J Med 1997; 336: 1689-96.

23. The RAPPORT Investigators. Randomized, placebo-controlled trial of platelet glycoprotein IIb/IIIa blockade with primary angioplasty for acute myocardial infarction. Circulation 1998; 98: 734-41.

24. The CAPTURE Investigators. Randomized, placebo-controlled trial of abciximab before and during coronary intervention in refractary unstable angina: the CAPTURE study. Lancet 1997; 349: 1429-35.

25. The EPISTENT Investigators. Randomized placebo-controlled and balloon-angioplasty-controlled trial to assess safety of coronary stenting with use of platelet glycoprotein IIb/IIIa blockade. Lancet 1998; 352: 87-92.
26. Stella PR, Kiemeneij F, Laarman GJ, OdekerkenD, Slagboom T, Van der Wieken R. Incidence and outcome of radial artery occlusion following transradial coronary angioplasty Cathet Cardiovasc Diagn 1997; 40: 156-8.

27. Kiemeneij F, Laarman GJ, Slagboom T. Percutaneous transradial coronary Palmaz-Schatz implantation guided by intravascular ultrasound. Cathet. Cardiovasc. Diagn 1995; 34: 133-6.

28. Saito S, Hosokawa G, Miyake S, Tanaka S, Kawamistu K, Ikei H. Experiences of Transradial coronary intervention in Shonan Kamakura General Hospital. Ninth Complex Coronary Angioplasty Course Book, Edited by Jean Marco and Jean Fajadet. Paris, May, 1998.

29. Hinds KL, Kauffman DM, Drinkwater VL. Transradial catheterization reduces nursing time and intensity in patients undergoing cardiac catheterization. Circulation 1996; 94: 2091.

30. Guidelines for percutaneous transluminal coronary angioplasty. A report of the American College of Cardiology/American Heart Association Task Force on Assessment of Diagnostic and Therapeutic Cardiovascular Procedures (Subcommittee on Percutaneous Transluminal Coronary Angioplasty). J Am Coll Cardiol 1988; 12: 529-45

31. Ellis SG, Vandormael MG, Cowley MJ, et al. Coronary morphologic and clinical determinants of procedural outcome with angioplasty for multivessel coronary disease. Implications for patient selection. Multivessel Angioplasty Prognosis Study Group. Circulation 1990; 82: 1193-202. 